\title{
O EXAME CELPE-BRAS: DISCUSSÕES PRELIMINARES SOBRE ALGUMAS LIMITAÇÕES E USOS
}

\section{CELPE-BRAS EXAMINATION: PRELIMINARY DISCUSSIONS ON SOME LIMITATIONS AND USES}

Natalia Moreira Tosatti ${ }^{1}$

\section{RESUMO}

O presente trabalho faz parte uma pesquisa em andamento que tem como propósito analisar o desempenho de candidatos ao Programa Estudantes Convênio (PEC), oriundos de Países Africanos de Língua Oficial Português (PALOP), no exame de proficiência em língua portuguesa, Celpe-Bras. Considerando o construto em que se baseia o exame e os seus propósitos avaliativos, questionamos o uso desse exame como instrumento adequado para medir a proficiência desses estudantes. Apresentaremos aqui nossas primeiras impressões e algumas problematizações, a partir dos dados fornecidos até o momento pelo Instituto Nacional de Estudos e Pesquisas Educacionais Anísio Teixeira (INEP), instituição responsável pelo exame.

\section{Palavras-Chave}

Celpe-Bras. Política linguística. PEC-G. PALOP

\section{Abstract}

This paper is part of an ongoing research that aims to analyze the performance of candidates to the Programa Estudante Conzênio (PEC-G), coming from african countires where Portuguese is an oficial language, in the Celpe-Bras examination (Proficiency in Portuguese as a Foreign Language). Considering the construct on which the exam is based and its evaluative purposes, we question the use of this exam as an appropriate instrument to measure the proficiency of these students. Here we will present our first impressions from the data collected so far.

\section{KeYwORDS}

Celpe-Bras. Language Policy. PEC-G. PALOP

1 Doutoranda em Letras pela Universidade Federal de Minas Gerais - UFMG. 


\section{INTRODUÇÃo}

Tratar sobre política linguística é abrir um cardápio diversificado de temas transversais e complexos como sociedade, currículo, avaliação, poder entre tantos outros que o compõem e que envolvem o universo "língua". Neste artigo abordaremos o assunto a partir de uma discussão sobre a exigência do Certificado de Proficiência em Língua Portuguesa para Estrangeiros (Celpe-Bras) a estudantes candidatos ao Programa Estudantes Convênio (PEC), oriundos de Países Africanos de Língua Oficial Português (PALOP).

Para se candidatar a esse convênio, até 2013, a comprovação de proficiência, por meio do Celpe-Bras, era uma exigência feita apenas aos candidatos estrangeiros não-lusófonos. Porém, a partir da publicação do Decreto n. 7.948, de 12 de março de 2013, a exigência do exame se estendeu a todos os estudantes estrangeiros, sem exceção. Interessante ressaltar que no item 1.8 do Edital n. 72, de 31 de julho de $2019^{2}$, consta a informação de que a "participação no Celpe-Bras 2019/2 é voluntária, destinada a estrangeiros e brasileiros, residentes no Brasil ou no exterior, cuja língua materna não seja a Língua Portuguesa".

Ainda que pertencentes a um contexto plurilíngue, o português pode ser a língua materna de muitos desses participantes, logo haveria aí uma contradição entre a exigência aos candidatos ao PEC-G e o exame. Segundo dados coletados da página da Divisão de Assuntos Educacionais do Ministérios de Relações Exteriores, no período de 2000 a 2019, 56\% dos estudantes selecionados para o PEC-G veem dos PALOP.

O que justificaria uma mudança nas exigências a esse grupo a partir de 2014? Como seria o desempenho desse público em um exame de desempenho que busca aferir a proficiência por meio de tarefas que simulam ações que poderiam ocorrer no cotidiano? Haveria diferença relevante entre o desempenho na parte escrita e na parte oral?

Essas perguntas motivaram um estudo de doutorado, ora em andamento, que busca compreender, então, se o Celpe-Bras é o instrumento de avaliação adequado para se medir a proficiência em língua portuguesa de examinandos vindos dos PALOP. Embora ainda não tenha respostas a essas problematizações, nos propomos neste artigo a apresentar algumas primeiras impressões.

\section{O exame Celpe-Bras}

Em um contexto mundial de circulação de informações e de pessoas, a língua se coloca como um importante meio de acesso a oportunidades. O domínio de certas línguas (e variações) garante prestígio e confere ideia de pertencimento a um grupo. Uma forma de se comprovar o domínio em uma língua é por meio de testes oficiais que, a partir de critérios - e visões de linguagem preestabelecidos - medem as habilidades de um indivíduo em determinado idioma.

A nota ou conceito alcançado, de acordo com os parâmetros do exame, irá atestar ou não a proficiência do indivíduo naquela língua, descrevendo a partir do nível obtido o que ele seria capaz de realizar naquela língua. Testes, sobretudo os de larga-escala, tornam-se instrumentos de poder, uma vez que os resultados provenientes desses testes orientam não só decisões pessoais, mas também da esfera pública.

2 Cf. http://bit.ly/2uefQQh. 
Shohamy (2006), ao tratar sobre exames de línguas, coloca-os como mecanismos de política linguística e os caracteriza como ideológicos, sociais e econômicos, uma vez que testes de proficiência podem ser mecanismos velados de manutenção e controle de relações de poder que se estabelecem através das línguas, pautando seu ensino, sua aprendizagem, sua avaliação e seus usos. Segundo a autora, "testes são mais poderosos quando são os indicadores individuais para determinar o futuro dos sujeitos. Como critérios de aceitação e rejeição, eles dominam outros dispositivos educacionais, como currículo, livro e ensino". (SHOHAMY, 1998, p. 331).

Testes de larga escala, portanto, representam um lugar de responsabilidade social, trazendo impacto para vida dos examinandos. Dessa forma seus usos devem estar de acordo com os objetivos a que se destina o exame, com base em seu construto.

Em relação a nossa discussão voltada à aplicação do Celpe-Bas a examinandos provenientes de países em que o português é língua oficial, Diniz e Bizon (2015) entendem que, pelos fundamentos que orientam a elaboração e uso do exame, seja um equívoco a escolha desse teste como instrumento para a avaliação do nível de proficiência desse público, uma vez que "ele não foi concebido visando a avaliação de primeira língua, de forma que sua aplicação para públicos diferentes daqueles para os quais foi desenhado traz dificuldades que mereceriam ser alvo de pesquisas" (DINIZ e BIZON, 2015, p. 153).

Os autores ainda questionam o fato de essa exigência servir a um processo de capitalização linguística do português brasileiro, uma vez que "o Estado brasileiro passa a avaliar o nível de proficiência em português de sujeitos que têm essa língua como materna ou de escolarização, contando, para tanto, com a parceria dos Centro Culturais Brasileiros (CCBs) dos PALOP”. Ainda segundo os pesquisadores, "esse processo, ao mesmo tempo que capitaliza o português brasileiro, descapitaliza outros portugueses, dando novos contornos aos processos de estigmatização sofridos pelos portugueses africanos (...)" (DINIZ e BIZON, 2015, p. 154).

A língua portuguesa se estende hoje por múltiplos territórios, assumindo status e situações sociolinguísticas diversificadas, podendo ser entendida como língua transnacional (ZOPPI-FONTANA, 2007, 2009).

Angola, Moçambique, Guiné-Bissau, Cabo Verde e São Tomé e Príncipe - e, mais recentemente, Guiné Equatorial - são países que compõem a chamada “África Lusófona”, sendo o português língua oficial nesses países. Isso significa que o português é um idioma que, de alguma forma, circula nesses países - na sua relação com diversas outras línguas.

Quando as pessoas se movem e se deslocam, seus recursos comunicativos são afetados por tais movimentos, e o que funcionaria bem em um determinado contexto do mundo pode não ser tão eficiente ou mesmo compreendido em outro, ainda que estejamos falando de uma mesma língua (DIAS e PINTO, 2017). Segundo Blommaert (2010) a mobilidade das pessoas envolve também a mobilidade da linguagem e de recursos sociolinguísticos. Para o autor, "padrões de uso da linguagem 'sedentários' ou 'territorializados' são complementados por padrões 'translocais' ou formas 'desterritorializadas' de uso da linguagem e que a combinação de ambas às vezes é responsável por inesperados efeitos sociolinguísticos” (BLOMMAERT, 2010 p. 4-5).

Ao colocar como foco de nossa discussão o exame Celpe-Bras, revisitamos a concepção bakthiniana da natureza social da linguagem. Na visão de Bakthin (2003), a linguagem acompanha as 
atividades humanas e se realiza por meio de gêneros - primários, lugar da comunicação cotidiana, da espontaneidade, e secundários, lugar da comunicação oficial, do "relativamente estável" - que se complementam, se compõem, se imbricam. Dentro desse universo estão locutores e interlocutores, sujeitos da História e de memória, que articulam linguagens em contextos e em papeis sociais variados e mutáveis. Além disso, dentro do gênero há ainda o diálogo cultural entre temporalidades históricas e espacialidades sociais diversas. Os gêneros são, então, abertos, e suas possibilidades são tão infinitas quanto o uso da língua em atividades humanas diversas.

No Celpe-Bras, todos os participantes são submetidos a um mesmo teste, dividido em duas partes: (i) uma Prova Escrita, com duração de 3 horas, composta por duas tarefas que integram a compreensão oral e produção escrita e outras duas que integram leitura e produção escrita; (ii) uma Prova Oral, com duração de 20 minutos, em que há a presença de dois avaliadores, um observador e um entrevistador, sendo que este último interage com o examinando, face a face, a partir das informações constantes da sua ficha de inscrição e a partir de elementos provocadores que tratam sobre assuntos do cotidiano.

Para obter o certificado, o examinando deve alcançar desempenho nas duas partes, sendo que os níveis de proficiência avaliados são: básico (sem certificação), intermediário, intermediário superior, avançado e avançado superior. Cada tarefa da Prova Escrita é avaliada por dois avaliadores que, com base em uma grade de avaliação, atribuem individualmente uma nota à tarefa. Em caso de discrepância maior que 2 pontos entre os avaliadores, a tarefa passa por um terceiro avaliador, coordenador daquela tarefa, geralmente membro da Comissão Técnico-Científica.

As tarefas da Parte Escrita são elaboradas a partir de textos autênticos e apresentam ao examinando um contexto de produção a partir do qual ele deverá realizar uma ação comunicativa, como escrever um e-mail destinado a empresários de uma região, propondo o apoio a uma ONG. Assim, a proficiência é medida a partir do cumprimento da tarefa, ou seja, avalia-se a adequação à situação comunicativa proposta, dentro do gênero discursivo apresentado.

No que se refere à Prova Oral do Celpe-Bras,

espera-se que o examinando tenha capacidade de conversar, da forma mais natural possível, sobre assuntos do cotidiano e da atualidade veiculados na mídia brasileira. Vale salientar que não se trata de uma entrevista na qual uma pessoa pergunta e a outra responde de forma mecânica, mas sim de uma simulação de conversa em língua portuguesa (BRASIL, 2015, p. 28).

A interação face a face é dividida em dois momentos: nos primeiros cinco minutos da interação, o examinando deve demonstrar capacidade de conversar sobre questões de natureza pessoal. No segundo momento, o examinando tem acesso a três elementos provocadores, previamente selecionados pela dupla de avaliadores, e, um por vez, esses elementos são apresentados ao examinando e discutidos, a partir de um roteiro de perguntas que compõe o material do exame. Para cada elemento provocador, são reservados cinco minutos para a sua leitura e para a interlocução.

A atribuição das notas é feita a partir dos seguintes aspectos:
a. compreensão da fala do entrevistador;
b. competência para interagir em Língua Portuguesa (o examinando deve apresentar de- senvoltura e autonomia durante sua produção oral);
c. fluência (capacidade de interagir sem interromper o fluxo da conversa); 
d. domínio de vocabulário e de estruturas da Língua Portuguesa (capacidade de usar vocabulário apropriado e estruturas adequadas do português nos diferentes temas abordados);

e. pronúncia (manter uma pronúncia adequada em relação aos sons, ritmo e entonação da língua portuguesa) (BRASIL, 2015, p. 22).

Todas as interações são gravadas em áudio e enviadas para o INEP, para consulta por parte de outra equipe de avaliadores, quando da existência de notas discrepantes. Considera-se discrepância quando a diferença entre as notas atribuídas pelos avaliadores ultrapassa 1 ponto, em uma escala de 0 a 5 , ou quando um avaliador atribui ao examinando uma nota que corresponde a uma faixa de certificação e, o outro avaliador, a outra faixa.

No exame, conforme destaca Schoffen (2009), a

proficiência é compreendida como capacidade de produzir enunciados adequados dentro de determinados gêneros do discurso, configurando a interlocução de maneira adequada ao contexto de produção e ao propósito comunicativo, e sua avaliação somente será válida se levar em conta a relação entre todos os aspectos que vão determinar a atualização do propósito de comunicação e da relação entre os participantes em diferentes contextos de comunicação (SCHOFFEN, 2009, p 5).

De acordo com o Manual do Examinando, a decisão de se elaborar uma única prova para certificar diferentes níveis de proficiência, contrariamente ao que ocorre em outros exames, baseia-se na premissa de que "examinandos/as de todos os níveis são capazes de desempenhar ações em Língua Portuguesa. O que pode variar é a qualidade desse desempenho, dependendo do nível de proficiência do/a examinando/a" (BRASIL, 2015a, p. 8). Scaramucci (2000) explica que há,

nesse caso, uma gradação de proficiência. Em vez de um conceito "absoluto", de tudo-ou-nada, temos um conceito "relativo", que procura levar em conta a especificidade da situação de uso futuro da língua. Em vez de uma proficiência única, absoluta, monolítica, baseada naquela do falante nativo ideal, teríamos várias, dependendo da especificidade da situação de uso da língua (SCARAMUCCI, 2000, p. 14).

Em relação aos candidatos a uma vaga ao PEC-G, o nível mínimo de proficiência exigido é o Intermediário, que é conferido

ao examinando que evidencia um domínio operacional parcial da língua portuguesa, demonstrando ser capaz de compreender e produzir textos orais e escritos sobre assuntos limitados, em contextos conhecidos e situações do cotidiano; trata-se de alguém que usa estruturas simples da língua e vocabulário adequado a contextos conhecidos, podendo apresentar inadequações e interferências da língua materna e/ou de outra(s) língua(s) estrangeira(s) mais frequentes em situações desconhecidas (grifo nosso) (BRASIL, 2015, p. 8)

Uma vez que no exame "não se busca aferir conhecimentos a respeito da língua por meio de questões sobre a gramática e o vocabulário, mas sim a capacidade de uso dessa língua" (BRASIL, 2011, p. 4), tínhamos a expectativa de que não seria um grande desafio para esses participantes alcançar o nível Intermediários de proficiência. Contudo, de acordo com dados fornecidos pelo Instituto Nacional de Estudos e Pesquisas Educacionais Anísio Teixeira (INEP), essa expetativa não se cumpriu. 
De acordo esses dados, as edições de 2015-2 e 2016-1 do exame Celpe-Bras contaram com 395 examinandos dos postos aplicadores dos PALOP (43 em Angola, 144 em Cabo Verde, 103 em Guiné-Bissau, 72 em Moçambique e 33 em São Tomé e Príncipe). Desses examinandos, 31\% não alcançaram nível de certificação e 35\% obtiveram certificação Intermediária, como pode ser observado no Quadro III, a seguir.

Quadro III - Nível de Certificação alcançado por Posto Aplicador

Edições 2015-2 e 2016-1

\begin{tabular}{|c|c|c|c|c|c|c|}
\hline País & $\begin{array}{c}\text { Total de } \\
\text { examinandos }\end{array}$ & $\begin{array}{c}\mathbf{\%} \\
\text { Sem } \\
\text { Certificação }\end{array}$ & $\begin{array}{c}\% \\
\text { Interm. }\end{array}$ & $\begin{array}{c}\mathbf{\%} \\
\text { Interm. } \\
\text { Sup. }\end{array}$ & $\begin{array}{c}\% \\
\text { Avançado }\end{array}$ & $\begin{array}{c}\text { Avançado } \\
\text { Superior }\end{array}$ \\
\hline Angola & 43 & 46 & 35 & 19 & 0 & 0 \\
\hline Cabo Verde & 144 & 10 & 35 & 35 & 2 & 18 \\
\hline Guiné-Bissau & 103 & 79 & 19 & 2 & 0 & 0 \\
\hline Moçambique & 72 & 10 & 38 & 30 & 4 & 6 \\
\hline $\begin{array}{c}\text { São Tomé e } \\
\text { Príncipe }\end{array}$ & 33 & 52 & 27 & 15 & 0 & 6 \\
\hline
\end{tabular}

Dados fornecidos pelo INEP em $2017^{3}$.

Percebemos que, em Angola, Guiné Bissau e São Tomé e Príncipe, é grande o percentual de examinandos que não atingiu o nível Intermediário, mínimo para a provação no PEC-G. É também relevante o percentual de examinandos que alcançou apenas esse nível mínimo de certificação, o que indica que, segundo os critérios de avaliação do exame, parte considerável desses participantes, que pretendem cursar a graduação em universidades brasileiras, apresenta "domínio operacional parcial da língua portuguesa".

Sendo hoje um instrumento de política linguística e de difusão da língua portuguesa, há que se estar atento aos usos que se têm feito do exame Celpe-Bras para que não se corra o risco do comprometimento de um exame ao aplicá-lo a um contexto ou público para o qual ele não foi desenhado. Dias e Pinto (2017) chamam a atenção para esse aspecto em artigo que trata sobre testes de língua no contexto de migração transnacional para o Brasil.

Alguns linguistas nos alertam ainda para o fato de que, além do propósito de medir conhecimentos linguísticos e de uso da língua, testes podem também se transformar em barreiras (gatekeepers) de acesso a direitos (Cf. BACHMAN, 2008; MCNAMARA et al., SHOHAMY, 2006).

Scaramucci (2000) ressalta que a ideia de proficiência em uma língua é às vezes confundida com o que se entende por "saber uma língua" e isso envolve contextos de uso. Logo, concordamos com a autora quando problematiza uma visão absoluta de proficiência defendendo que seria mais adequado falarmos de proficiências que assumem características distintas de acordo com as exigências de uso da língua determinadas pela situação comunicativa. Essa visão se aplica inclusive à proficiência em nossa própria língua materna e de escolarização. Quem é falante nativo língua portuguesa, mesmo tendo concluído nível de escolarização superior nessa língua, poderia assumir que é proficiente em qualquer situação de uso da língua?

3 Para o levantamento inicial de informações para a elaboração desta pesquisa o INEP, gentilmente, cedeu aos pesquisadores os dados apresentados no Quadro III. 
Assim, uma hipótese que levantamos em relação ao que consideramos baixo desempenho dos estudantes dos PALOP é que esses estudantes, embora tenham familiaridade com a língua portuguesa, talvez não tenham a mesma familiaridade com os gêneros propostos no exame. Nos países que compõem a África Lusófono, o português entrou como língua oficial a partir de 1975 e, em muitos desses países processos de escolarização se dão de forma distinta e, em algumas situações, com certo conflito em relação à língua oficial.

A partir dessa visão, suspeitamos que o problema seja mais relativo a uma questão de letramento que de proficiência em língua, já que no exame mais que negociação de significado espera-se também uma a demonstração de uma leitura crítica dos textos de insumo para a realização de tarefas que sugerem gêneros como artigo de opinião, carta do leitor, textos de divulgação, nos quais os participantes precisam assumir os papeis propostos dentro de cada tarefas, de acordo com a situação de comunicação nelas exigidas.

$\mathrm{Na}$ seção a seguir, apresentaremos primeiras impressões construídas com base na análise de dados fornecidas pelo INEP para a realização de nossos estudos.

\section{Primeiras impressões e algumas discussões}

O corpus desta pesquisa é composto, principalmente, por produções orais e escritas de examinandos provenientes dos PALOP, da edição de 2018 do exame ${ }^{4}$. Neste artigo trataremos da análise de produções escritas referentes à Tarefa 1 dessa edição.

O vídeo da tarefa em análise ${ }^{5}$ teve como texto-base uma reportagem televisiva, com duração de 3 minutos e 30 segundos, que tratava do tema "Segurança das urnas eletrônicas". No enunciado, solicitou-se a produção de um artigo, no qual o participante deveria assumir o papel de um representante do Tribunal Superior Eleitoral, defendendo a segurança da urna eletrônica, conforme pode ser visto na imagem 1 a seguir.

Imagem 1

Tarefa 1 da Edição 2018 do Exame Celpe-Bras

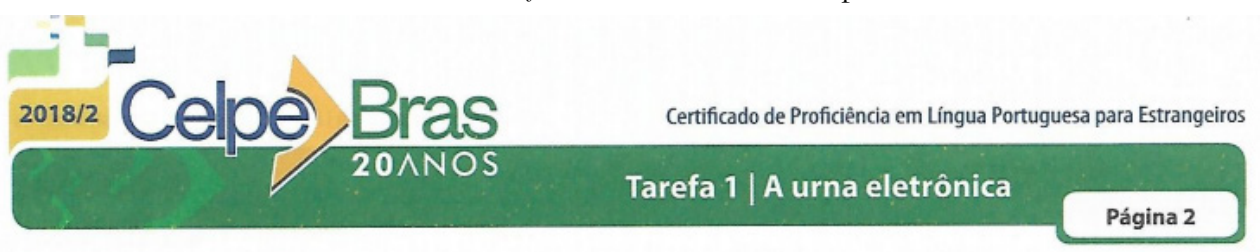

Você vai assistir duas vezes ao vídeo, podendo fazer anotaçöes enquanto assiste.

Disponivel em: Material de divulgaçäo TSE

Um jornal de circulaçăo nacional no Brasil está organizando um debate sobre a segurança do sistema eletrônico de votação. Como representante do Tribunal Superior Eleitoral (TSE), escreva um artigo defendendo a segurança da urna eletrônica.

4 Para acesso aos dados cumprimos todas as regras impostas pelo INEP para acesso a informações sigilosas, que deve ser feito sempre dentro da sala segura desse instituto. Os dados coletados são liberados apenas após análise do instituto de pesquisa. Até a data de submissão deste artigo, o INEP ainda não havia concluído tal análise. Por essa razão os dados serão descritos e não transcritos neste artigo.

5 O vídeo da tarefa está disponível em http://bit.ly/2QIL3CZ. 
Vicentini (2019), em trabalho sobre as tarefas de compreensão oral para produção escrita no Celpe-Bras, conclui que as condições de produção, tais como, propósito de escrita, gênero e interlocutores, são bem definidas no exame. O enunciado acima ilustra essa afirmação, uma vez que deixa claro o gênero a ser elaborado (artigo de opinião), sob que perspectiva (representante do TSE), com que propósito (defender a segurança da urna eletrônica) e para quem (público em geral, uma vez que o texto será publicado em um jornal de circulação nacional).

Para a realização dessa tarefe, não basta que o participante compreenda as informações fornecidas do insumo. É preciso que ele saiba articulá-las dentro das possibilidades de um artigo de opinião. O fato de o enunciador ser um representante do TSE, confere a ele autoridade para emitir as opiniões que comporão o texto. Além disso, é esperado que em um artigo de opinião haja interação - que pode ser estabelecida de forma direta ou indireta - com o leitor.

O artigo de opinião é um gênero textual que expõe a opinião de um enunciador que se vale da argumentação para apresentar, analisar, avaliar, discutir, defender ou refutar uma determinada ideia ou ponto de vista. Geralmente, aborda um tema atual de relevância para os leitores e para o momento. Faraco e Tezza (1992) afirmam que defender uma opinião pressupõe argumentos ou provas, e construir um bom texto argumentativo é apresentar o outro lado, para melhor fundamentar o próprio lado.

$\mathrm{Na}$ circunstância do exame, tais informações estão presentes no texto de insumo, no caso a reportagem a que os participantes assistem duas vezes para realizar a tarefa. Assim, na tarefa, para que se possa comprovar a compreensão oral dos participantes, é fundamental que eles façam uso dos dados apresentado no vídeo. A realização de tarefas assim requer do examinando habilidades diversas que vão além da compreensão da língua, é preciso também ter letramento crítico para que a atividade seja realizada com êxito.

A grade de correção da tarefa é elaborada por uma equipe de especialistas no ensino de português como língua estrangeiras e antes da correção das produções, a partir de uma amostra de textos produzidos durante aquela edição, ajustes são feitos, com base no desempenho demonstrado pelos participantes. Assim, certamente, não é esperada a produção de um artigo perfeito, mas que o texto obedeça a critérios estabelecidos dentro das premissas do exame.

O que a análise de um total de 100 textos de examinandos que realizaram a prova em Postos de Angola, Cabo Verde, Moçambique, Guine Bissau e São Tomé e Príncipe, mostrou é que houve uma diferença grande de posto para posto, no desempenho da tarefa. Essa diferença se dá, principalmente, em relação à adequação ao gênero.

$\mathrm{Na}$ amostra de 10 textos de Angola, 10 textos de São Tomé e Príncipe e 30 textos de Guine Bissau, a maioria dos examinandos elaborou textos em que não havia posicionamento explícito, delimitação clara do tema ou marcas de interlocução, comprometendo, assim, o cumprimento do propósito da tarefa. Já nas amostras de 30 textos de Moçambique e 30 textos de Cabo verbo o mesmo não ocorreu. Os textos oriundos desses postos de aplicação, em sua maioria, atenderam ao que foi solicitado.

O que nos chamou atenção foi o fato de que nos textos de menor desempenho o problema, nem sempre, era relativo ao desconhecimento da língua, mas de dificuldade na estruturação de ideias em um gênero pouco familiar a eles. 
Bizon (2013) em trabalho que narra processos de territorialização de estudantes candidatos ao programa PEC-G destaca em alguns depoimentos e entrevistas uma visão que, segundo a pesquisadora "tende a imobilizar o estrangeiro PEC-G, inclusive o 'lusófono', posicionando-o como aquele que não tem nada a oferecer, como aquele que "não sabe" e que, portanto, "precisa aprender"” (BIZON, 2013, p. 206).

No caso do estudante lusófono, pode ser que a ele tenha sido oferecido o instrumento equivocado para que ele pudesse demonstrar o conhecimento que tem da língua. Como uma primeira impressão, parece-nos que não haveria problema de uso da língua, mas de adequação ao instrumento.

Neste ponto da investigação, conclusões ainda são prematuras, mas alguns questionamentos já podem ser levantados. Se o PEC-G é um programa de cooperação acadêmica que oferece oportunidades de formação superior a cidadãos de países em desenvolvimento com os quais o Brasil mantém acordos educacionais e culturais, não seria mais adequado uma formação em letramentos acadêmicos de forma mais inclusiva?

Schohamy (1993, p. 1) defende que

o papel dos testes não termina na fase de desenvolvimento, quando atingem alta confiabilidade e validade; em vez disso, eles precisam seguir os usos dos testes e examinar questões de utilidade, relevância, ética e interpretação. Os avaliadores não podem mais ser vistos como técnicos cujo trabalho é realizado quando atingem coeficientes de confiabilidade satisfatórios; em vez disso, devem considerar as consequências sociais, psicológicas, éticas, curriculares e educacionais dos testes que produzem.

Muito trabalho de análise ainda há pela frente. Nas próximas etapas, além dos textos das demais tarefas do exame, analisaremos uma amostra também do desempenho oral de parte dos examinandos que compõe o nosso corpus de pesquisa. Verificaremos se há discrepância entre a produção oral e escrita desses participantes.

O Celpe-Bras é um exame válido e confiável, com um construto sólido e tarefas coerentes com o que o teste se propõe a avaliar. Deixamos claro que nosso questionamento não tem foco no exame, mas no uso que tem sido feito desse instrumento. Parece-nos equivocada a exigência do Celpe-Bras para examinandos oriundos de países em que o português é língua oficial e que têm que demostrar proficiência dentro de uma maneira particular de aprender uma língua.

Essa exigência valoriza um determinado padrão de língua e uma determinada forma de aprender, colocando-se, talvez, mais peso nas diferenças que nas semelhanças. A constatação de uma baixa proficiência por meio de um teste não gera soluções para o problema. Pelo contrário, aumenta distâncias e reforça uma visão preconceituosa e até neocolonialista em relação à língua portuguesa.

\section{REFERÊNCIAS}

BACHMAN, L. F. Fundamental considerations in language testing. Oxford, England: Oxford University Press. 1990.

BAKTHIN, M. Estética da criação verbal. São Paulo: Martins Fontes, 2003.

BIZON, A. C. Narrando o Exame Celpe-Bras e o convênio PEC-G: a construção da territorialidade m tempos de internacionalização. Tese (Doutorado em Linguística). Instituto de Estudos da Linguagem, Universidade Estadual de Campinas, Campinas, 2013. 
BLOMMAERT, J. The sociolinguistics of globalization. New York, NY: Cambridge

University Press, 2010.

BRASIL. Ministério da Educação. Manual do Examinando, 2015. Disponível em http://bit.ly/2QYhWvF. Acesso em 05 de ago. de 2016.

Presidência da República. Casa Civil. Subchefia para Assuntos Jurídicos. Decreto n. 7.948, de 12 de março de 2013. Disponível em: http://bit.ly/3517F1p. Acesso em: 15 mai. 2016.

DINIZ, L. R. A. Política linguística do Estado brasileiro para a divulgação do português em países de língua oficial espanhola. Trabalhos em Linguística Aplicada, Campinas, v. 51, n. 2, 2012, p. 435-458.

FARACO, C. A. e TEZZA, C. Prática de texto para estudantes universitários. Petrópolis, RJ: Vozes, 1992

McNAMARA, T. Communication and the design of language tests. In. Language Testing. Oxford, 2000.

ORLANDI, E. P. Teorias da linguagem e discurso do multilinguíssimo na contemporaneidade. In: ORLANDI. E. P. (Org.). Política Linguística no Brasil. Campinas: Pontes, 2007.

DIAS, A. L. K. e PINTO, J. P. Ideologias linguísticas e regimes de testes de língua para migrantes no Brasil. Rev. bras. linguist. ap1., Belo Horizonte, v. 17, n. 1, 2017, p. 61-81. Disponível em http://bit. ly/2ZOixUq. Acesso em 6/out./2019.

SCARAMUCCI, M. V. R. Proficiência em LE: considerações terminológicas e conceituais. Trabalhos em Linguística Aplicada, n. 36, 2000, p. 11-22.

SCHOFFEN, J. R. Gêneros do discurso e parâmetros de avaliação de proficiência em português como língua estrangeira no exame Celpe-Bras. 2009. 192 f. Tese de Doutorado, Universidade Federal do Rio Grande do Sul, Porto Alegre, 2009.

SHOHANNY, E. Language policy: hidden agendas and new approaches. Londres/Nova Iorque, NI: Routledge, 2006.

Critical language testing and beyond. Studies in Educational Evaluation, Tel Aviv, Israel: Pergamon. vol. 24, n. 4, 1998, p. 331-345.

The power of tests: the impact of language tests on teaching and learning. NFLC Occasional Papers, jun. 1993.

VICENTINI. M. P. As tarefas de compreensão oral para produção escrita no Celpe-Bras: construto e operacionalização. In: Revista Estudos Linguísticos, v. 48, n. 1, 2019, p. 561-580. 